\title{
Seismic Activity and Seismic Cone Tectonics on the West Coast of the United States
}

\section{Lijun Chen}

Research Center of Earthquake Prevention and Disaster Reduction Engineering of Hunan Province (Retired), Changsha, China Email: seisman@foxmail.com

How to cite this paper: Chen, L. J. (2019). Seismic Activity and Seismic Cone Tectonics on the West Coast of the United States. Journal of Geoscience and Environment Protection, 7, 92-112. https://doi.org/10.4236/gep.2019.711007

Received: September 14, 2019

Accepted: November 18, 2019

Published: November 21, 2019

Copyright () 2019 by author(s) and Scientific Research Publishing Inc. This work is licensed under the Creative Commons Attribution International License (CC BY 4.0).

http://creativecommons.org/licenses/by/4.0/

\begin{abstract}
In the west coast of the United States, there are frequent strong earthquakes and volcanic activities in the crust, high accuracy of the earthquake catalogue, so it is the best choice to study prediction of strong earthquakes and volcanoes, and there are two different types of seismic cone tectonics, volcanic type and intracrustal strong seismicity type, so it becomes the epitome of global earthquake prediction research, rarer. In this paper, according to the data of ANSS earthquake catalogue in the United States, using the Seismo-Geothermic Theory and its methods, the images were processed such as the planar distribution images and the three-dimensional images of the general earthquakes, subcrustal earthquakes, intracrustal strong earthquakes and volcanic eruption and the sequence diagrams of subcrustal earthquakes in the study area, as well as theory explanation of their relations with the San Andreas Fault. According to this idea, the volcanic origin and precursory information of U01 mini seismic cone tectonic were firstly studied, then the causes of intracrustal strong seismicity of U02 mini seismic cone tectonic and their migration rules were studied. The precursory information of M7.1 earthquake on July 6, 2019, was analyzed and summarized in U02 mini seismic cone tectonic, and a basic method for handling similar events in the future was given. In this paper, it thinks strong earthquake and volcanic disaster are from deep mantle heat energy, rather than the result of the independence movement of surface structure. Therefore, it finds the most natural energy of causes of seismicity and volcanic activity and opens a new direction for the prediction research of earthquakes and volcanoes.
\end{abstract}

\section{Keywords}

Seismo-Geothermic Theory (Seismo-Geothermics), Mini Seismic

Cone Tectonic, Intracrustal Strong Earthquake, Subcrustal Earthquake, Volcano 


\section{Introduction}

The west coast study area of the United States, located at $20^{\circ} \mathrm{N}-52^{\circ} \mathrm{N}$ and $132^{\circ} \mathrm{W}-90^{\circ} \mathrm{W}$, covers the border areas of Canada and Mexico with the United States and is located south of the global 24th North American Cone Tectonic (Figure 1). An M 7.1 earthquake occurred at 03:19:52 (UTC) on July 6, 2019, 18 $\mathrm{km}$ west of Searles Valley, California $\left(35.770^{\circ} \mathrm{N}, 117.599^{\circ} \mathrm{W}\right)$, with a focal depth of $8 \mathrm{~km}$. In the previous 34 hours, a 6.4 magnitude quake had struck $11 \mathrm{~km}$ to the northwest. The author thought that, if only within the scope of around $50 \mathrm{~km}$ and the strike-slip properties of fault to discuss the cause of the earthquake (USGS, 2019) has great limitations, should be based on the principle of Seismo-Geothermic Theory (Chen, 2000, 2012a, 2013a; Chen et al., 2013) and it's working methods (Chen, 2013b, 2015a, 2015b, 2015c, 2016a, 2016b, 2016c, 2016d; Chen et al., 2015a, 2015b), must study the seismic cone tectonic of the west coast of the United States and the relationship with the San Andreas Fault, and open up a new direction for the future of earthquake prediction research (Chen, 2019a).

At present, there are two mainstream schools of study on earthquake prediction in the global seismology. One is the plate theory, which uses collision and subduction to understand the cause of global strong earthquakes and volcanoes. Colliding at a rate of a few centimetres per year is not enough to fuel the Earth's cataclysm, nor is it known where the energy of plate collisions from or when

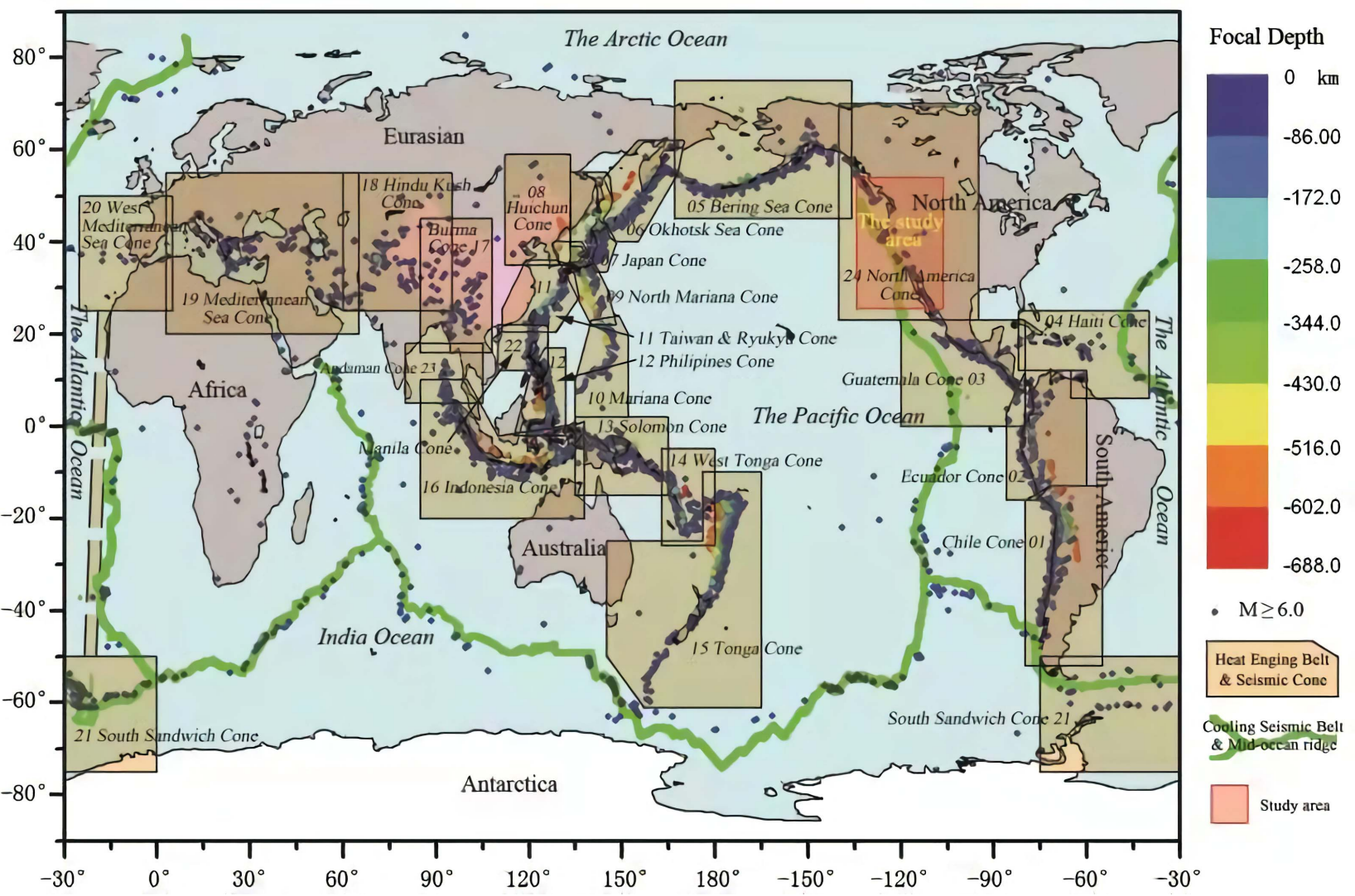

Figure 1. The geographical location of the west coast study area. 
they will happen. At the same time, the theory of subduction is inconsistent with the rule of the bottom-up and layer-by-layer drive of subcrustal seismic activity. As a result, predictions of earthquakes and volcanoes fall into the realm of agnosticism. Another school of thought, represented by fault genesis, believes that earthquakes are predictable and uses earth rotation and interplanetary relations to find energy for fault activities. However, this energy is not enough to cause catastrophic events on the Earth, much less to trigger earthquakes of hundred kilometres in deep (References are omitted).

According to the source depth data of high-precision earthquake catalogue, the author discovered the seismic cone tectonics, divided 24 inverted straight cones with the maximum depth of $200-650 \mathrm{~km}$, as the material foundation and energy platform of the Seismo-Geothermics, so as to study the relationship between earthquakes, volcanoes and seismic cone tectonics. It is found that more than $95 \%$ of intracrustal strong earthquakes and all seismic cone volcanic eruptions on the Earth occur within 24 Seismic Cone Tectonics. They are the result of the accumulation and driving layer-by-layer of heat energy from the deep of the Earth along the seismic cone tectonics, so as to finally push the surface tectonic movement. Of course, the movement of seismic cone tectonic is extremely complex, including the subcrustal seismic activity, heat conduction and convection, and is obviously affected by the Earth rotation, interplanetary relations and other factors, which shows up as the Mantle Decadal Oscillations. However, the movement of seismic cone tectonic is quite different from that of inherited surface tectonic movement. The former is in a closed state, unable to dissipate energy, and finally can only promote the surface tectonic movement, causing disaster, while the latter is in semi-infinite space, ready to creep, continental drift, or small earthquakes, mud volcanoes and other ways to release energy, will not cause disaster. As for the relationship between intracrustal strong earthquakes and volcanoes, people usually think of them as two different fields of study, but the Seismo-Geothermics says that they are just two different ways in which seismic cone tectonics release the energy of cone body.

Therefore, there are two types of near-surface tectonic movements. One kind is the inherent, inherited tectonic movement caused by the Earth rotation, interplanetary relations and other factors directly affected, manifested as gradual change. One is the forced movement on the near-surface structure also affected by the Earth rotation, interplanetary relations and other factors (Mantle Decadal Oscillation) resulting in the energy accumulation of seismic cone tectonic, which is manifested as catastrophe. The superposition of the two types of tectonic movements constitutes the M-type Heat Engine Belt composed of the all of seismic cone tectonics on the Earth's surface (Chen, 2012a). In this paper, many interesting phenomena can be found by using the principle and methods of the Seismo-Geothermics, broking people's conventional ideas, such as the lava capsule of the volcano, the genesis and tectonic action of the San Andreas fault, the migration of intracrustal strong earthquakes, the relationship between intracrustal strong earthquakes and volcanoes, the Mantle Decadal Oscillations, the 
strong prediction function of subcrustal focal depth sequence diagram, the essence of continental drift, and so on.

\section{Data and Methods}

\subsection{Data analysis and Processing Methods}

Seismic analysis methods of the Seismo-Geothermics, first of all, according to the definition of seismic cone tectonics select earthquake catalogue in the study area, and then using the planar distribution of earthquakes and volcanic activity, the three-dimensional distribution and temporal distribution of depth, research overall activity characteristics in the seismic cone tectonic and activity characteristics in the separable mini seismic cone tectonics respectively, summarizes the precursor information of past events and provide the working method and experience for the prediction of subsequent events. With the same accuracy of the original data, the result of this method is unique and repeatable.

\subsection{Data}

\subsubsection{Selection of Seismic Catalogue}

The research principle and method of Seismo-Geothermics depend entirely on the seismic catalogue with high accuracy source depth data. For this purpose, the ANSS (Advanced National Seismic System) Comprehensive Earthquake Catalogue (ComCat) is used. The catalogue, from the Northern California Earthquake Data Center, selects the period is 1965-2019.7 and includes 320,605 M2.0+ seismic records from the study area. Address:

https://earthquake.usgs.gov/earthquakes/search/ (before 2004) and https://earthquake.usgs.gov/earthquakes/search/\#site-sectionnav (since 2004).

\subsubsection{On the Focal Depth}

The accuracy of seismic source depth can be obtained from the ANSS seismic catalogue (Chen, 2019b). The ANSS directory contains M1.0+ earthquakes throughout the United States. According to preliminary statistics, the depth within $50 \mathrm{~km}$, most of the seismic depth measurement errors are within the degree of $\pm 1 \mathrm{~km}$; for those with a depth of more than $50 \mathrm{~km}$, the depth measurement error of most earthquakes is in the order of $\pm(1-2) \mathrm{km}$, with a few errors of $\pm 10+\mathrm{km}$, which is generally tolerable.

What we need to get is not the absolute depth of the source, but the reasonable dispersion of the $0-650 \mathrm{~km}$ depth seismic activity from the theory and method, that is, the relative source depth.

\subsubsection{Applicability Analysis of Seismic Catalogue}

According to the ANSS seismic catalogue, the seismic data collected in the study area are shown in Table 1. Table 1 contains the total number of earthquakes in the study area and the two subcrustal earthquake intensive areas.

As can be seen from Table 1:

1) The maximum depth of the overall earthquake in the research area of the 
Table 1. Seismic statistics of the study area collected from the ANSS seismic catalogue.

\begin{tabular}{|c|c|c|c|c|}
\hline Study area & Mmin & Mmax & Frequency & $\begin{array}{l}\text { Focal depth } \\
\text { Hmax }(\mathrm{km})\end{array}$ \\
\hline \multirow{6}{*}{$\begin{array}{c}\text { The west coast, } \\
\text { USA }\end{array}$} & 2 & 7.3 & 320,605 & 650 \\
\hline & 3 & & 51556 & 217.43 \\
\hline & 4 & & 9273 & 121.31 \\
\hline & 5 & & 1133 & 102.97 \\
\hline & 6 & & 117 & 57 \\
\hline & 7 & & 10 & 17.43 \\
\hline \multirow[t]{6}{*}{ U01 area } & 2 & 7.0 & 24,277 & 102.21 \\
\hline & 3 & St. HELENS volcano & 7236 & 91.39 \\
\hline & 4 & & 2798 & 62 \\
\hline & 5 & & 395 & 62 \\
\hline & 6 & & 41 & 57 \\
\hline & 7 & & 1 & 12 \\
\hline \multirow[t]{6}{*}{ U02 area } & 2 & 7.3 & 278,185 & 650 \\
\hline & 3 & & 39,796 & 217.43 \\
\hline & 4 & & 6080 & 121.31 \\
\hline & 5 & & 664 & 102.97 \\
\hline & 6 & & 66 & 33 \\
\hline & 7 & & 9 & 17.43 \\
\hline
\end{tabular}

west coast of the United States can reach $650 \mathrm{~km}$, and the earthquake set seems to be able to form multiple vertical inverted cones, meeting the requirements of the concept of seismic cone tectonic.

2) In the study area, there are two concentrated areas projected by the surface of subcrustal earthquakes. One has a maximum focal depth of $102 \mathrm{~km}$ and has both Intracrustal Strong Earthquakes and an active volcano (Smithsonian Institution, 2015). The other has a maximum focal depth of $650 \mathrm{~km}$, which causes frequent intracrustal strong earthquakes. Both earthquake sets can form upside-down conical structures that meet the structural requirements of mini seismic cone tectonic.

3) In view of the current scientific and technological level of the earthquake catalogue, Seismo-Geothermic Theory is currently most concerned about the time and location of future strong earthquake activities in the shell, not considering the energy relationship, so do not make excessive requirements for the magnitude-frequency relationship of related earthquake sets.

\section{Results}

\subsection{The General Description of Seismicity and Volcanic Activity on the West Coast of the United States}

\subsubsection{Horizontal Distribution of Seismicity and Volcanic Activity on the West Coast of the United States}

The surface plane distribution of earthquakes and volcanoes in the study area 
according to the ANSS seismic catalogue is shown in Figure 2. The picture includes the total earthquakes, subcrustal earthquakes and intracrustal strong earthquakes, as well as an active volcano, St. HELENS Volcano. Subcrustal earthquake refers to the earthquake of source depth $35+\mathrm{km}$, which is the global average crustal thickness, the intracrustal strong earthquake refers to the M6.8+ earthquake in the shell.

In Figure 2, a schematic diagram of the San Andres Fault is compiled based on relevant data (Huang, 2003; Luo et al., 1987). The San Andreas Fault is a right-lateral strike-slip fault, extending at least $1287 \mathrm{~km} \mathrm{NW}$-SE, and most of the strong earthquakes in the crust occur in this fault zone or its associated faults (Table 2, Figure 2).

Mount St. Helens is located $154 \mathrm{~km}$ south of Seattle at the coordinates of $46.20^{\circ} \mathrm{N}$ and $122.18^{\circ} \mathrm{W}$, with an altitude of $2549 \mathrm{~m}$. It has erupted successively in 1980 and 2004, and the largest eruption index VEI $=6$ in history. According to the classification method of the author, this volcano belongs to the seismic cone volcanic eruption (Chen, 2016d, 2016e, 2016f), and the maximum eruptive plume can reach more than $10,000 \mathrm{~m}$.

\subsubsection{Surface Plane Distribution Characteristics}

As can be seen from Figure 2, the biggest feature of the study area is that the subcrustal earthquake is projected onto the surface as two concentrated areas, namely U01 and U02. The seismic activity range in the shell of the two units is

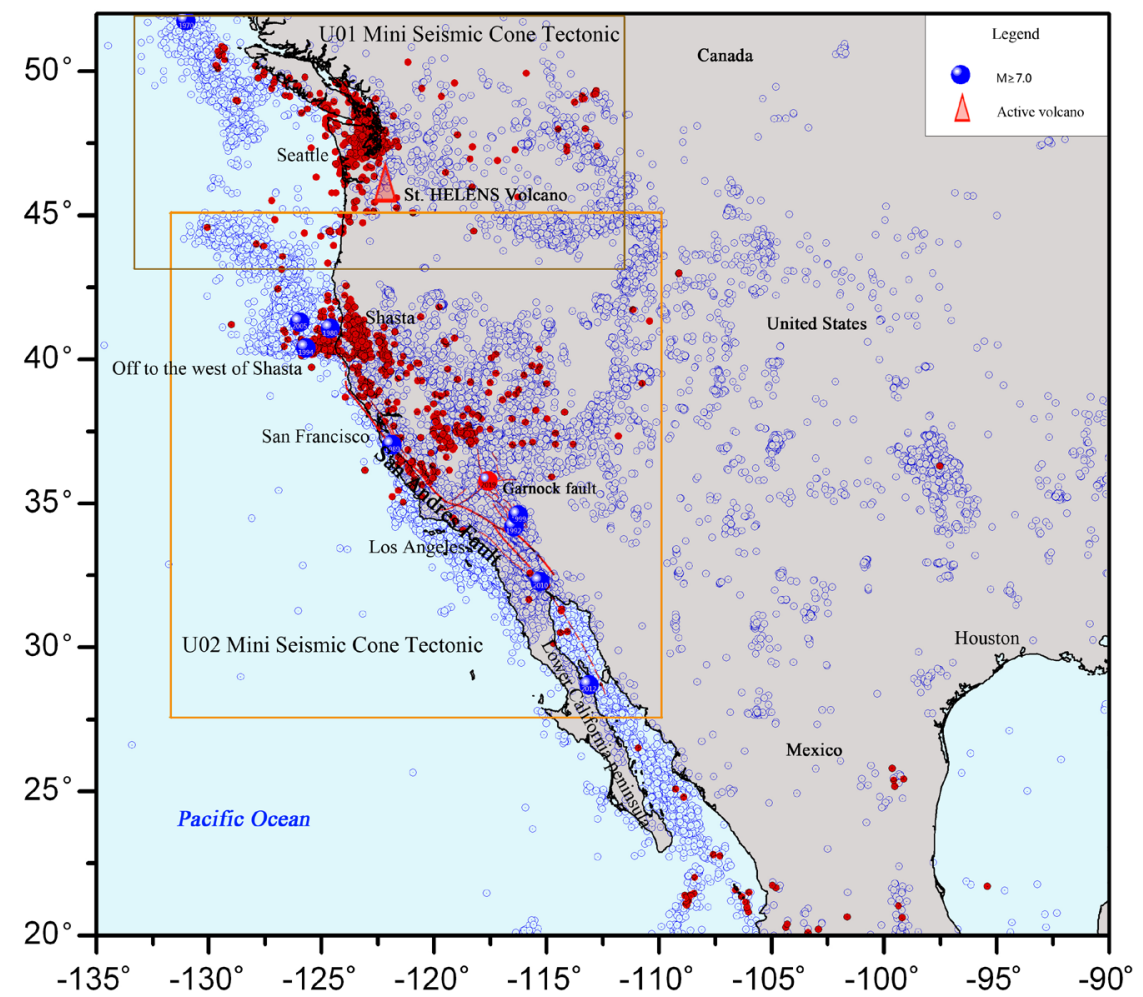

Figure 2. Distribution of earthquakes and volcano in the study area on the west coast of the United States (1965-2019.7, M 2 2.0; Volcano data by Smithsonian Institution (2015)). 
Table 2. Strong earthquakes in the west coast region of the United States from ANSS seismic catalogue (1965-2019, $\mathrm{M} \geq 6.8)$.

\begin{tabular}{cccccccc}
\hline No. & Time & $\begin{array}{c}\text { Longitude } \\
{ }^{\circ} \mathrm{E}\end{array}$ & $\begin{array}{c}\text { Latitude } \\
{ }^{\circ} \mathrm{N}\end{array}$ & $\begin{array}{c}\text { Depth } \\
(\mathrm{km})\end{array}$ & $\mathrm{M}$ & Division & Reference place \\
\hline 1 & 1965.325 & -122.4 & 47.4 & -57 & 6.88 & $\mathrm{U} 01$ & Seattle \\
2 & 1970.478 & -131.024 & 51.753 & -12 & 7 & $\mathrm{U} 01$ & \\
3 & 1976.903 & -125.709 & 41.289 & -15 & 6.8 & $\mathrm{U} 02$ & Off to the west of Shasta \\
4 & 1980.854 & -124.6157 & 41.0842 & -14.64 & 7.2 & $\mathrm{U} 02$ & Off to the west of Shasta \\
5 & 1980.961 & -129.496 & 49.479 & -10 & 6.8 & $\mathrm{U} 01$ & \\
6 & 1989.795 & -121.8798 & 37.0362 & -17.43 & 7 & $\mathrm{U} 02$ & San Francisco \\
7 & 1992.49 & -116.437 & 34.2 & -0.97 & 7.3 & $\mathrm{U} 02$ & Los Angeles \\
8 & 1994.667 & -125.68 & 40.402 & -10 & 7 & $\mathrm{U} 02$ & Off to the west of Shasta \\
9 & 1995.135 & -125.539 & 40.556 & -10 & 6.8 & $\mathrm{U} 02$ & Off to the west of Shasta \\
10 & 1999.79 & -116.271 & 34.594 & -0.02 & 7.1 & $\mathrm{U} 02$ & Los Angeles \\
11 & 2001.161 & -122.7267 & 47.149 & -51.9 & 6.8 & $\mathrm{U} 01$ & Seattle \\
12 & 2005.452 & -125.953 & 41.292 & -16 & 7.2 & $\mathrm{U} 02$ & Off to the west of Shasta \\
13 & 2009.588 & -112.903 & 29.039 & -10 & 6.9 & $\mathrm{U} 02$ & Lower California peninsula \\
14 & 2010.257 & -115.2953 & 32.2862 & -10 & 7.2 & $\mathrm{U} 02$ & Searles Valley \\
15 & 2012.28 & -113.104 & 28.696 & -13 & 7 & $\mathrm{U} 02$ & Lower California peninsula \\
16 & 2014.187 & -125.1338 & 40.8287 & -16.441 & 6.8 & $\mathrm{U} 02$ & Off to the west of Shasta \\
17 & 2018.806 & -129.289 & 49.3346 & -10 & 6.8 & $\mathrm{U} 01$ & \\
\hline & 2019.51 & -117.599 & 35.770 & -8 & 7.1 & $\mathrm{U} 02$ & \\
\hline & & & & & & & \\
\hline
\end{tabular}

Note: Decimal time in the table includes years, month, day, hours, minute and second, accurate to minute.

obviously larger than that under the shell, which is equivalent to the canopy of the seismic cone tectonic. The subcrustal earthquake concentrated area is surrounded by the intracrustal earthquake concentrated area, which shows that the subcrustal earthquake activity is in a straight down erect state, without obvious inclination, which is equivalent to the trunk part of the seismic cone tectonic, similar to be the inverted cone.

Surface tectonics, such as the San Andres Fault, can affect seismic activity within the crust, but not beneath it. On the contrary, subcrustal seismic activity can affect strong seismic activity within the crust of the fault zone.

The right-handed strike-slip property of the San Andreas Fault seems to be explained by reference (Chen, 2013b). According to the annual observation results of global GPS, Chen (2013b) pointed out in the article that "The tectonic movement of the global surface today is manifested as follows: the eastern hemisphere as a whole rotates clockwise, while the western hemisphere as a whole rotates counterclockwise, and the dominant rate is $2-7 \mathrm{~cm} / \mathrm{a}$, which jointly divides the Atlantic Ocean and oppresses the Pacific Ocean. It's a typical continental drift". Therefore, the NW strike faults in the eastern hemisphere, such as 
the Xianshuihe Fault, are mostly left-lateral strike-slip faults (Luo et al., 1987), while the NW strike faults in the western hemisphere are mostly right-lateral strike-slip faults.

As it turns out, the San Andres Fault is simply an existing crack in the top of the U02 Mini Seismic Cone Tectonic. Therefore, it is not a source of strong seismic activity in the shell, but only a tool for releasing cone energy in U02 Mini Seismic Cone Tectonic (see details later).

\subsubsection{The Three-Dimensional Image of Seismicity and Volcanic Activity on the West Coast of the United States}

The three-dimensional image of seismicity and volcanic activity on the west coast of the United States, based on the ANSS seismic catalogue, is shown in Figure 3. As can be seen from the figure, the subcrustal earthquakes are of straight type, and the deep earthquakes are all attributed to each other, with the deepest reaches of $650 \mathrm{~km}$, and the overall performance is an inverted cone. A Benioff profile from the Pacific Ocean to a seismically dense area of the North American continent would appear to tilt the ocean toward the continent, but it would be an illusion because it is a vertical inverted cone.

According to the source depth of the ANSS M4.0+ earthquakes, the maximum depth of North America is only $96 \mathrm{~km}$ and the shallowest, so it was named as No. 24 North American Seismic Cone Tectonic. However, the actual maximum depth is $650 \mathrm{~km}$.

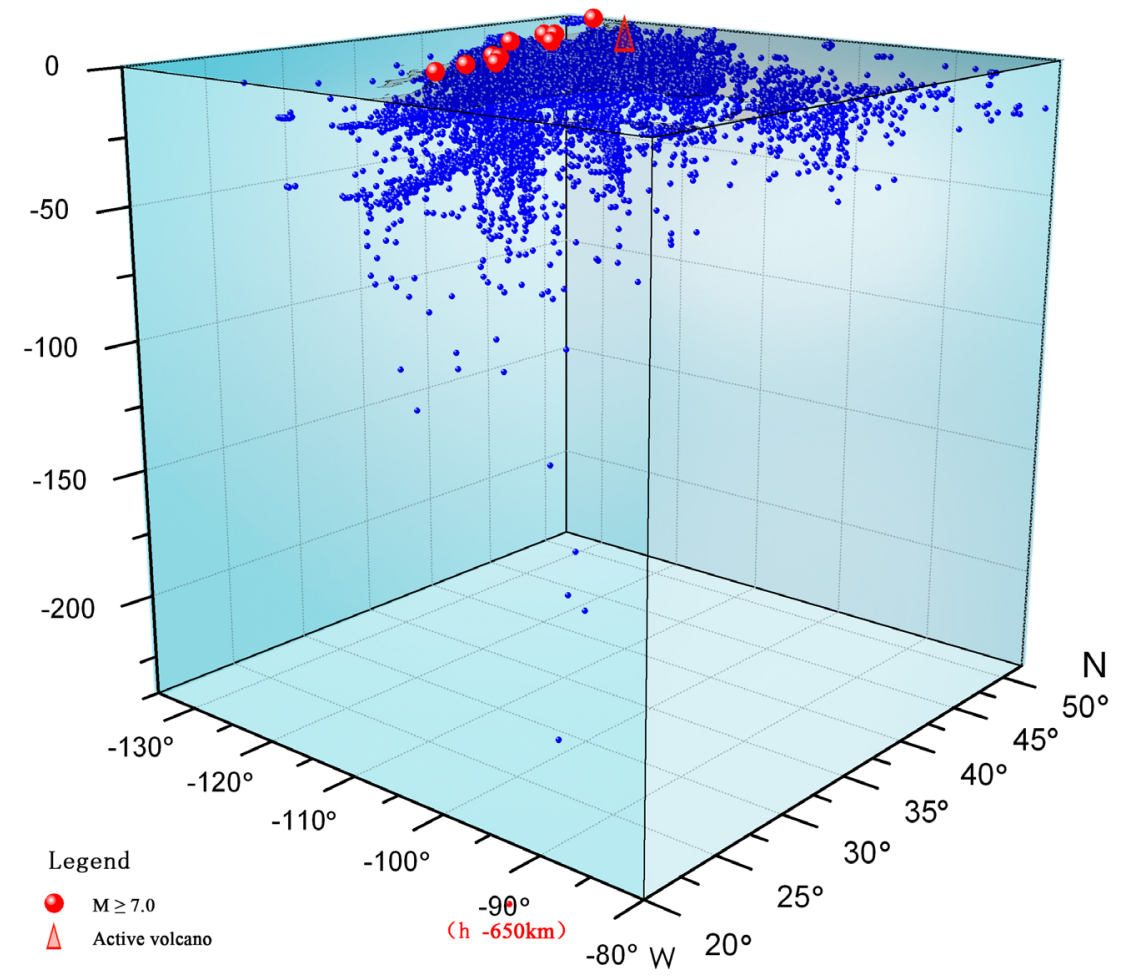

Figure 3. The three-dimensional image of seismicity and volcanic activity on the west coast of the United States (1965-2019.7, intracrustal earthquake $M \geq 3.0$, subcrustal earthquake $M \geq 2.0$ ). 


\subsubsection{On Mini Seismic Cone Tectonic in the Study Area}

Mini seismic cone tectonic is the smallest geological unit of the seismic cone tectonic. The subcrustal seismic activity in the mini seismic cone tectonic is sufficient to independently control the relationship between volcanic activity and intracrustal strong seismic activity in the affected area, as well as the active law of intracrustal strong seismic activity along the faults. The study area can be divided into two mini seismic cone tectonics with different properties, U01 and U02. U01 belongs to a volcanic seismic cone tectonic while U02 belongs to an intracrustal strong earthquake seismic cone tectonic. All of them are with typical significance in global research. Under certain conditions, of course, the two types can be transformed into one another and are thus essentially one. The seismic set statistics of the two mini seismic cone tectonics in the study area are shown in Table 1.

\subsection{U01 Mini Seismic Cone Tectonic in the Study Area}

\subsubsection{The Three-Dimensional Image of U01 Mini Seismic Cone Tectonic}

The geographical coordinates of the U01 Mini Seismic Cone Tectonic are $133^{\circ} \mathrm{W}$ $112^{\circ} \mathrm{W}$ and $43^{\circ} \mathrm{N}-52^{\circ} \mathrm{N}$ at the border of the United States and Canada. The seismic set of the mini seismic cone tectonic is shown in Table 1 and the threedimensional image is shown in Figure 4.

As can be seen from the image, the main body of the mini seismic cone tectonic is located under Mount St. Helens. Because active volcanoes are generally

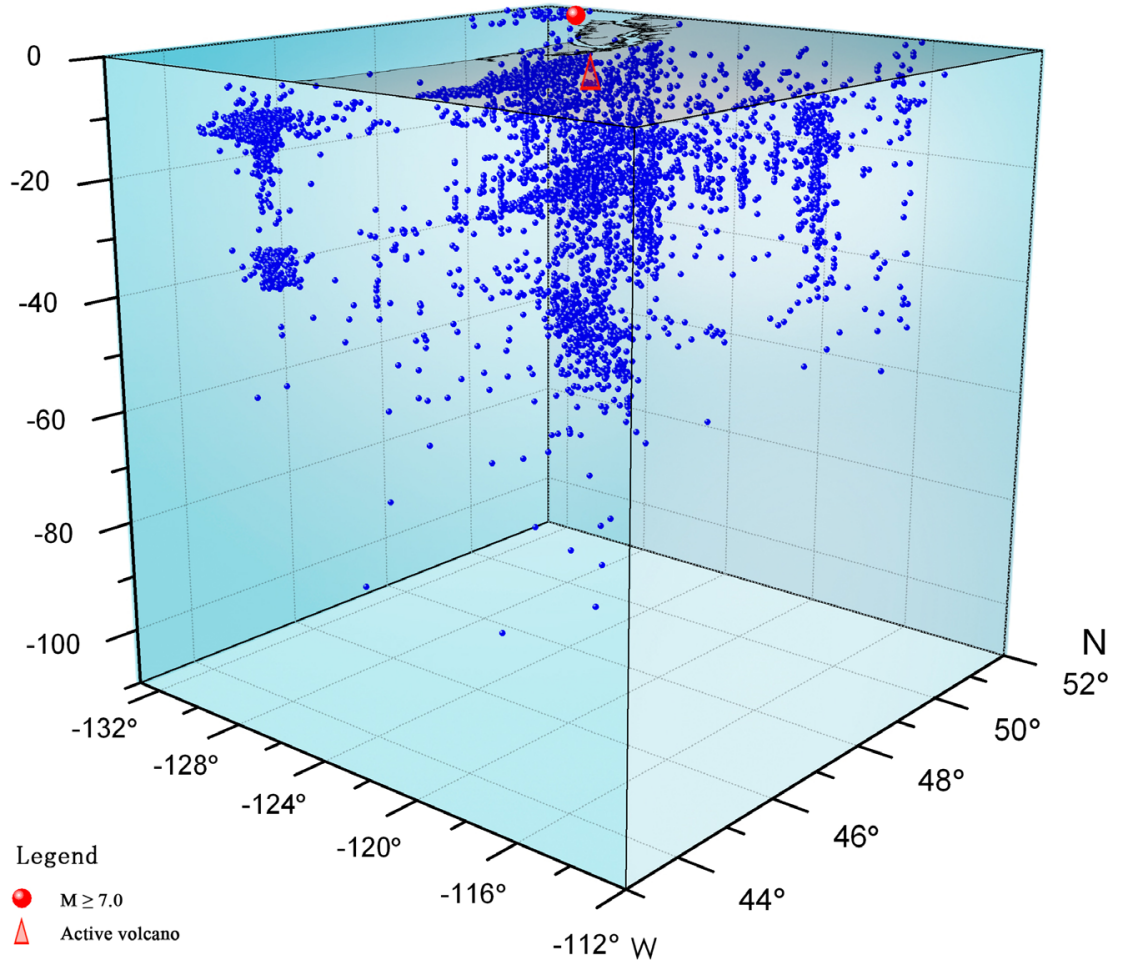

Figure 4. The primary model of U01 Mini Seismic Cone Tectonic (1965-2019.7, intracrustal earthquake $M \geq 3.0$, subcrustal earthquake $M \geq 2.0$ ). 
located near the place out of the Erath of a seismic cone tectonic, the seismic cone tectonic mainly controls the rules of volcanic activity, and the intracrustal strong earthquake is only a concomitant activity. The concomitant intracrustal strong earthquake is mostly to balance the energy level in the cone body. Strong seismic activity and volcanic activity are two different forms of energy released by seismic cone tectonics, just like a pair of twin brothers, one releases mechanical energy, the other releases heat energy directly.

\subsubsection{The Focal Depth Sequence Diagram of U01 Mini Seismic Cone Tectonic}

The focal depth sequence diagram of U01 Mini Seismic Cone Tectonic is shown in Figure 5.

It can be seen from the figure that the sequence diagram shows a certain trend of strong earthquakes and volcanic activities in the shell of this area. As the time frame of the data grows, the relationship will become clearer.

Another feature of the figure is the clustering of seismic activity under the shell of M2.0+. The first cluster began in 1970 and ended in 1994, followed by a powerful subcrustal earthquake in 2001 and a volcanic eruption in 2004. The second cluster began in 1998 and has been active for more than 20 years. After the 6.8 magnitude earthquake in 2018, the seismic activity under the shell of the cluster has not decreased. Obviously, it cannot fully release the energy of the cone body, so it deserves close attention.

The third characteristic is that the intensity of strong earthquake activity in the shell of this area is not very strong, and the volcanic activity is very intense, it can be seen that this seismic cone tectonic is mainly volcanic activity, followed

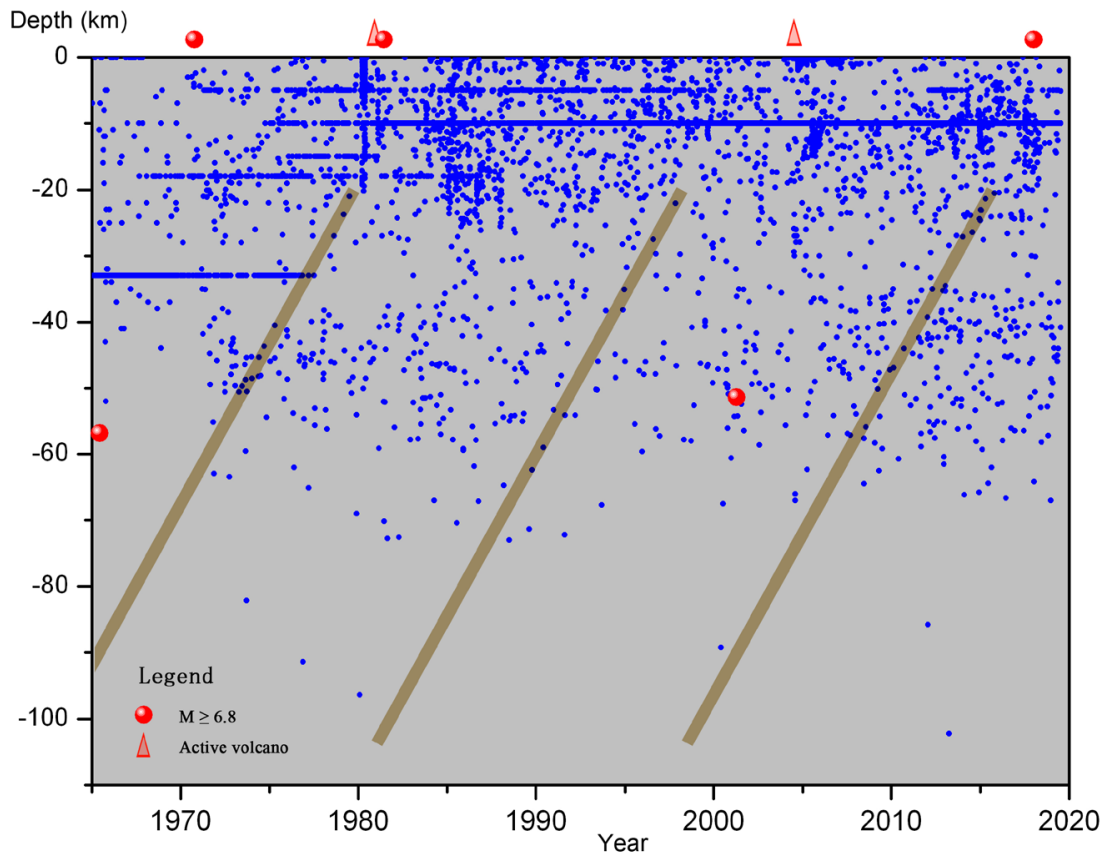

Figure 5. Focal depth sequence diagram of U01 Mini Seismic Cone Tectonic (1965-2019.7, intracrustal earthquake $M \geq 3.0$, subcrustal earthquake $M \geq 2.0$ ). 
by intracrustal strong earthquakes. Therefore, U01 Mini Seismic Cone Tectonic should belong to a volcanic seismic cone tectonic at least for now.

\subsection{U02 Mini Seismic Cone Tectonic in the Study Area}

U02 Mini Seismic Cone Tectonic is located at $132^{\circ} \mathrm{W}-110^{\circ} \mathrm{W}, 27.5^{\circ} \mathrm{N}-45^{\circ} \mathrm{N}$, covering a wide area between the northern San Francisco and the southern Los Angeles. The area is one of the most earthquake-prone in the Western United States. The seismic set of the mini seismic cone tectonic is shown in Table 1.

\subsubsection{The Three-Dimensional Image of U02 Mini Seismic Cone Tectonic} The three-dimensional image of U02 Mini Seismic Cone Tectonic is shown in Figure 6. The figure shows obvious characteristics of seismic cone tectonic, the maximum focal depth of $650 \mathrm{~km}$, is an inverted cone, nearly upright. Strong earthquakes occur frequently in this structure, and 13 destructive earthquakes of M6.8+ have occurred since 1965 (Table 2). Therefore, U02 Mini Seismic Cone Tectonic should belong to an intracrustal strong earthquake seismic cone tectonic at least for now.

\subsubsection{The Focal Depth Sequence Diagram of U02 Mini Seismic Cone Tectonic}

The focal depth sequence diagram of U02 Mini Seismic Cone Tectonic is shown in Figure 7. It can be seen from the figure that the tendency of seismic activity under the shell has an obvious control effect on the activity of strong earthquakes inside the shell. As seismic data grow, the role of such controls will become clearer.

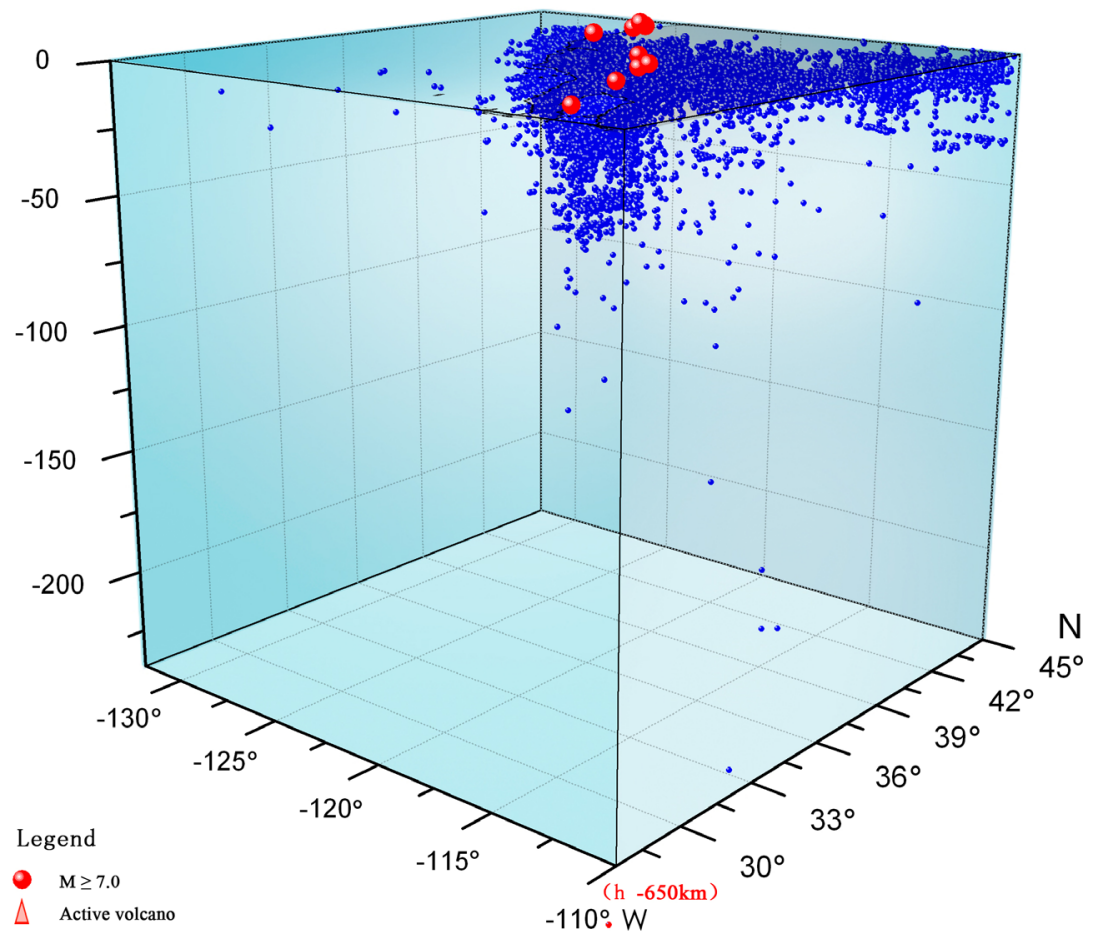

Figure 6. The primary model of U02 Mini Seismic Cone Tectonic (1965-2019.7, intracrustal quake $M \geq 3.0$, subcrustal quake $M \geq 2.0$, intracrustal strong quake $M \geq 7.0$ ). 


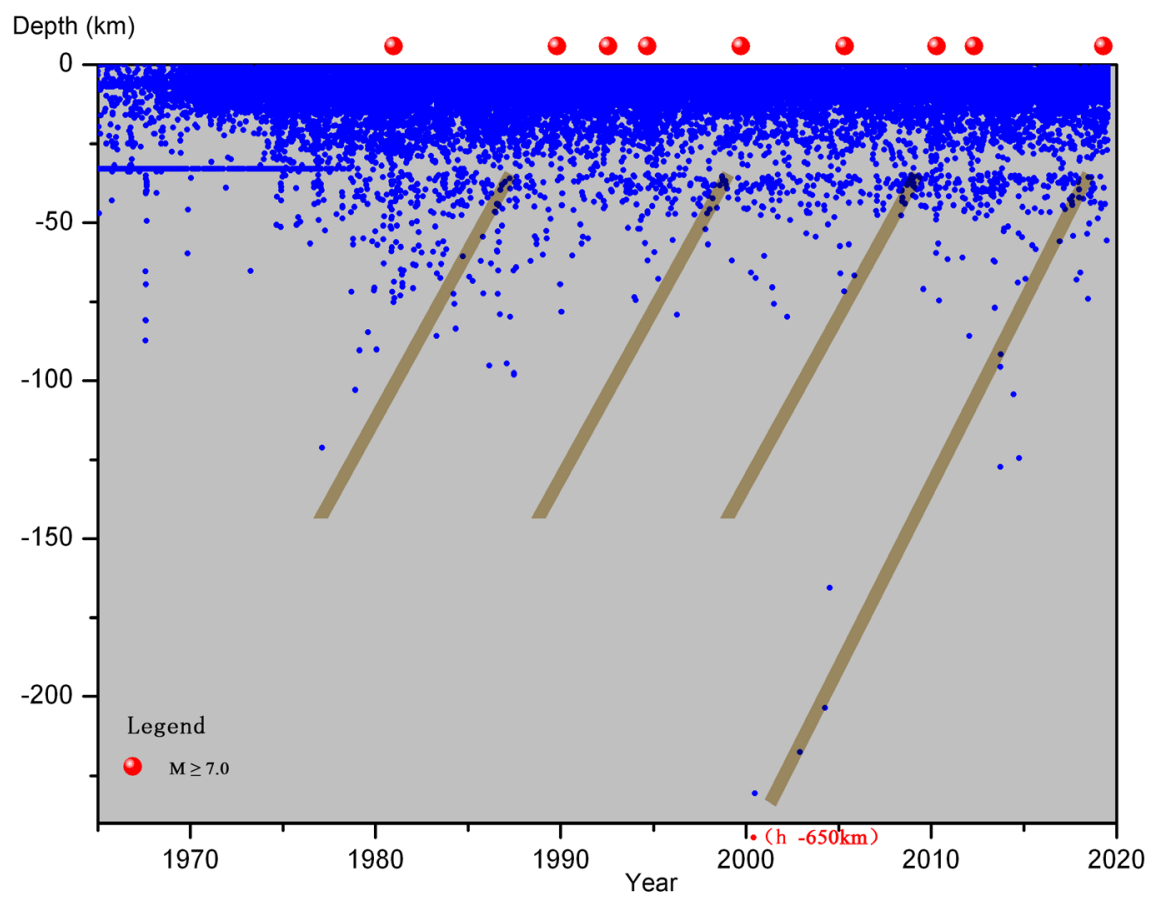

Figure 7. The focal depth sequence diagram of U02 Mini Seismic Cone Tectonic (1965-2019.7, intracrustal quake $M \geq 3.0$, subcrustal quake $M \geq 2.0$ ).

Before the M7.1 earthquake on July 6, 2019, since 2000, subcrustal seismic activities started from $650 \mathrm{~km}$ deep and gradually approached the crust, eventually pushing the tectonic movement and the strong earthquake in the crust. A complete trend diagonal line is shown here, as well as important precursor information for the M7.1 earthquake. Trend-slant lines indicate that seismic activity is ascending from the bottom rather than subducting from the top.

There is a rhythm of about 10 years of the trend line of subcrustal seismic activity, namely Mantle Decadal Oscillation (MDO) (Chen, 2013c, 2013d). The Mantle Decadal Oscillation is the main basis of time prediction for intracrustal strong earthquakes or volcanoes.

On January 5, 2012, author published in science blog post "A preliminary study of earthquake prediction methods for the west coast of the United States", the west coast of the United States earthquake activity was divided into two research areas in the blog, San Francisco area and Los Angeles area, the conclusion respectively "Along the San Andreas Fault in future 1 - 2 years there is little possibility of magnitude 7 earthquake in the San Francisco area", and "After the earthquake in 2010, under the shell still seems to have earthquake activity, so this area is worthy of scrutiny" for the Los Angeles area, the results was an M6.2 and an M6.9 earthquakes in the Gulf of California on April 12, 2012, which is referred to in the region of the blog post (Chen, 2012b, 2012c).

\subsection{Earthquake Precursors of M7.1 on July 6, 2019}

The focal depth sequence diagram in Figure 7 shows that there is an evident sign for M7.1 earthquake and work well is predictable. Therefore, it is necessary 
to take this earthquake as an example to extract the precursory phenomena.

\subsubsection{The Subcrustal Seismic Activity in 19 Years before M7.1 Earthquake}

The spatial distribution of subcrustal seismic activity in 19 years before M7.1 earthquake is shown in Figure 8.

Figure 2 shows the seismic data collected in 54 years. It can be seen from the figure that the subcrustal seismic activity in the U02 Mini Seismic Cone Tectonic is projected onto the surface and is roughly divided into two bands, one near the coastline (the outer zone) and the other inland (the inner zone). The subshell seismic activity in Figure 8 is concentrated in the second band and points directly to the epicentre of the M7.1 earthquake. It is known that the NW trending San Andreas Fault is right-handed strike-slip, so according to the principle of mechanics, the NEE intersecting San Andreas Fault must be left-handed strikeslip. The USGS earthquake report shows that the mechanism of M7.1 earthquake is right-handed strike-slip in the NW nodal plane and left-handed strike-slip in the NEE nodal plane (USGS, 2019), which conforms to the inherited tectonic movement program in this region. Therefore, it can be considered that it is the energy accumulated by the subcrustal seismic activity in the inner zone drives the inherited tectonic movement (Garnock fault) in this region.

As noted above, the right-handed strike-slip nature of the San Andreas Fault is related to the counterclockwise rotation of the western hemisphere, but the annual continental drift shown by GPS in the tens of millimetres can only be drift or creep, rather than catastrophic. Only the energy of the subcrustal earthquakes

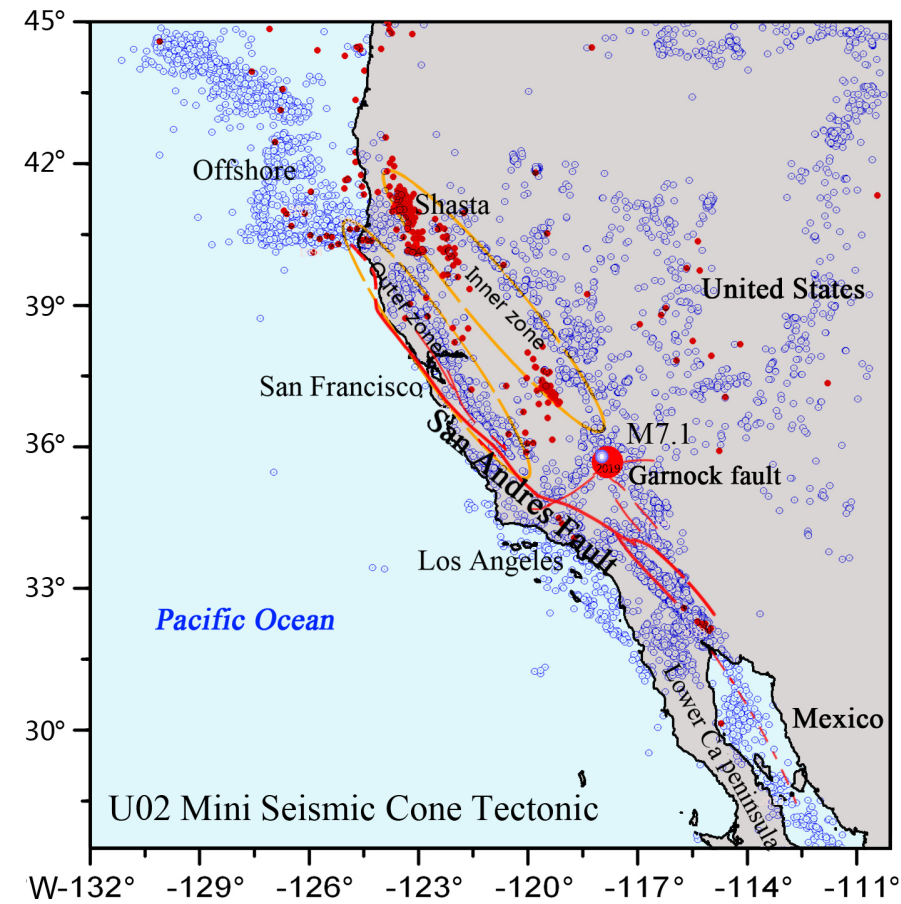

Figure 8. The subcrustal seismic activity distributions in 19 years before the 2019 M7.1 earthquake (2000-2019.7, intracrustal quake $M \geq 3.0$, subcrustal quake $M \geq 2.0$ ). 
accumulated in the short period is likely to cause such a catastrophic case. The energy released by the subcrustal earthquakes cannot be dissipated, but only accumulated up layer-by-layer, driven up layer-by-layer, and burst in the accumulation.

\subsubsection{The Relationship between the Projections of the Subcrustal Earthquakes and the Intracrustal Strong Earthquakes in the Outer} Zone and the Inner Zone

The subcrustal seismic projection is made as to the surface distribution map according to the three short trend lines in Figure 7, as shown as in Figures 9-11 respectively.

Figure 9 shows the period from 1976 to 1992. It can be seen that there are subcrustal seismic activities in both the outer and inner zones, so M7+ strong seismic activity has been observed in the offshore area west of Shasta, San Francisco and Los Angeles.

Figure 10 shows the period from 1994 to 1999 . Only the inner zone activity projected by the subcrustal earthquakes can be seen. Therefore, M7+ strong earthquake activity was observed in the offshore area west of Shasta and Los Angeles.

Figure 11 shows the period from 1999 to 2007 . Only the inner zone activity projected by the subcrustal earthquakes can be seen. Therefore, M7+ strong earthquake activity can be seen in the offshore west of Shasta and the south of Los Angeles, California bay and Lower California peninsula.

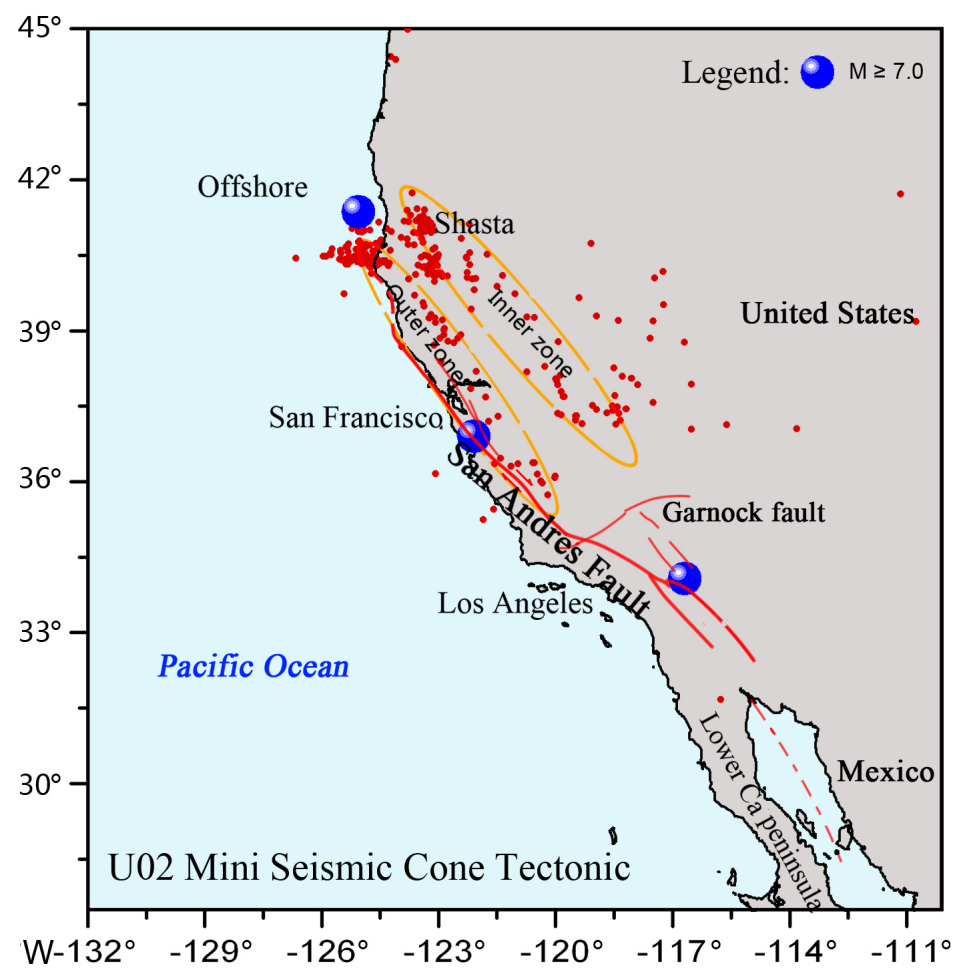

Figure 9. The surface projection belt of subcrustal earthquakes and the intracrustal strong earthquakes (I) (1976-1992, subcrustal earthquake M2.0+). 


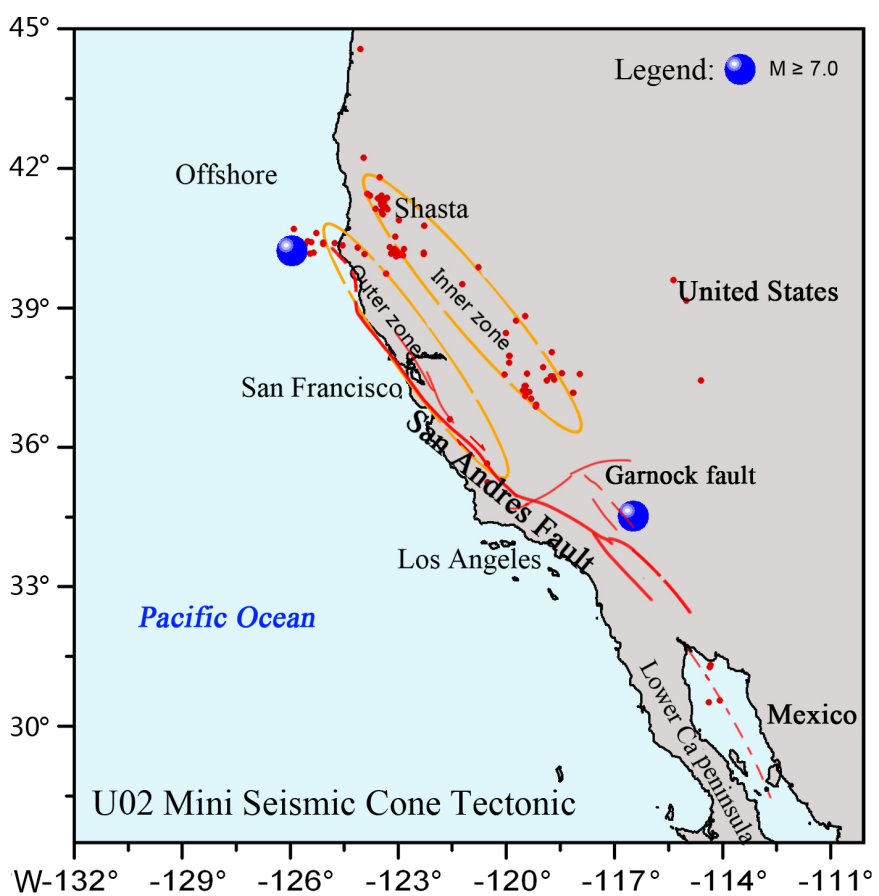

Figure 10. The surface projection belt of subcrustal earthquakes and the intracrustal strong earthquakes (II) (1994-1999, subcrustal earthquake M2.0+).

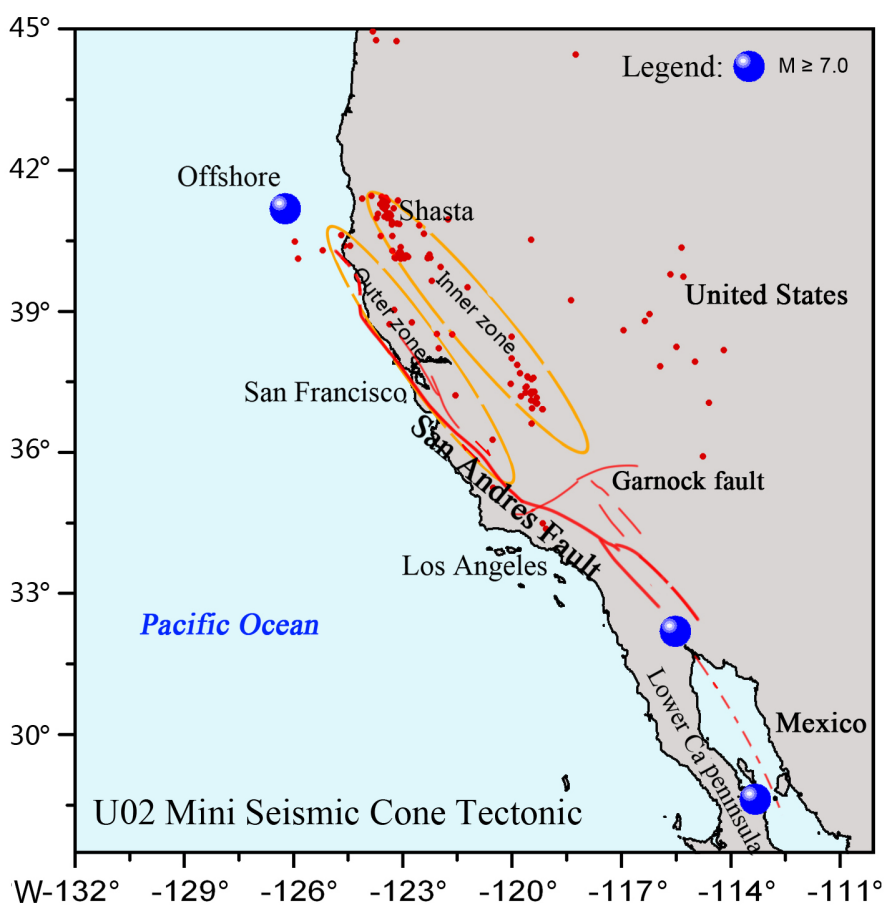

Figure 11. The surface projection belt of subcrustal earthquakes and the intracrustal strong earthquakes (III) (1999-2007, subcrustal earthquake M2.0+).

Thus it can be seen that the outer zone of the subcrustal seismic projection mainly controls the straight line of the San Andreas Fault from the offshore west of Shasta to the northern Los Angeles, while the inner zone of the subcrustal 
seismic projection mainly controls the turn section from the northern Los Angeles to the Gulf of California. The 2019 M7.1 earthquake was controlled by the inner zone.

\subsubsection{Migration of Intracrustal Strong Earthquakes along the San Andreas Fault}

Since 1965, there have been 13 M6.8+ intracrustal strong earthquakes along the San Andres Fault. Excluding the repetition of the same site, there have been a total of 10 migration processes, as shown in Figure 12.

The centre position of the migration was in the offshore of west Shasta Mountain. Because this is the northern end of the San Andres Fault, the inherited tectonic movement needs to continue extending from one end to the other, as well as overcome the blocking in the middle.

As a result, the 13 M6.8+ destructive earthquakes were all along the San Andres Fault line, bouncing around on either side or in between. This is because the energy accumulated in the seismic cone tectonic is released only through the weakest parts on the Earth. The San Andres Fault is large and tends to accumulate strain energy during the counterclockwise rotation of the western hemisphere, causing some areas to lock up. The two are in tune, ready to explode.

The migration of intracrustal strong earthquakes has obvious regularity. Transfer hub is at the north end, which is the base camp, jump to the middle or south section of the fault, and then return to the base camp. The cycle never ends.

After the 9th jump from the southern Lower California peninsula back to the

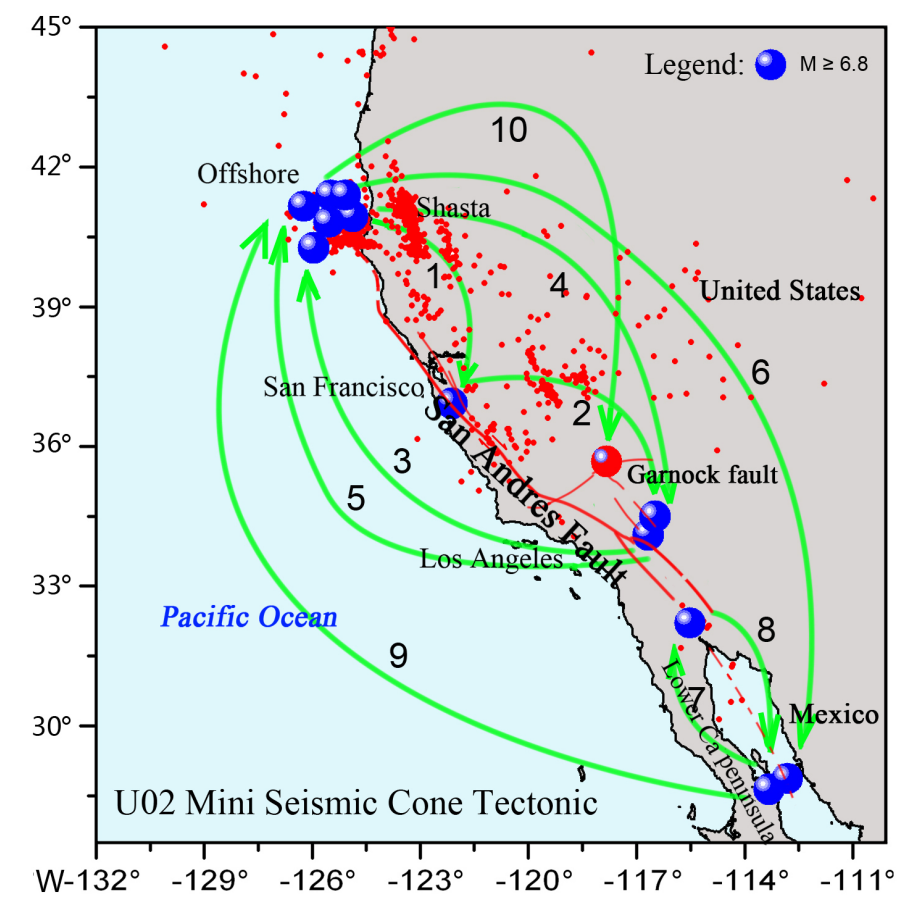

Figure 12. The migration map of intracrustal strong earthquakes along the San Andreas Fault (1965-2019.7, subcrustal earthquake $M \geq 2.0$ ). 
base camp, there are only two possibilities for the 10th migration. One is to repeat in situ, and the other is to move to the middle or southern section. Historically, migration is most likely to occur in the middle.

Therefore, the 11th migration in the future is more likely to return to the base camp if there is no repeat in situ.

\section{Discussions}

To sum up, one can see that there are precursors to intracrustal strong earthquakes and volcanoes. If the data in Figure 5 are longer, volcanoes in the U01 Mini Seismic Cone Tectonic may be predictable, while the data in Figure 7 show that intracrustal strong earthquakes of M7.1 in the U02 Mini Seismic Cone Tectonic are also evident signs. Therefore, it is necessary to summarize the precursory phenomenon and its prediction possibility.

\subsection{Preliminary Exploration of the Genesis of Mount St. Helens}

The Benioff profile is made according to the coordinates of Mount St. Helens $\left(46.20^{\circ} \mathrm{N}, 122.18^{\circ} \mathrm{W}\right)$ and the width of each side of the longitude and latitude line is $0.3^{\circ}$, as shown in Figure 13.

It can be seen from the figure that there is an inverted cone in the deep part of the volcano. The east-west profile is nearly upright, while the south-north profile is upright within $40 \mathrm{~km}$ depth, and then it slopes slightly to the north. The northward tilt may be related to the counterclockwise rotation of the western hemisphere. In other words, in the case of the western hemisphere's overall counterclockwise rotation, the upper layer, which is nearly $40 \mathrm{~km}$ thick, can rotate as a whole, while the lower layer has a drag effect.

The study found what appears to be a lava sac deep inside the volcano. Lava sacs are at least $1.2^{\circ}$ (longitude) $\times 0.6^{\circ}$ (latitude) $\times\left(20-40 \mathrm{~km}\right.$ altitude) $\mathrm{km}^{3}$. Subcrustal seismic activity is missing within the lava sac. Active volcanic eruptions generally occur near the centre position of the surface influence zone of
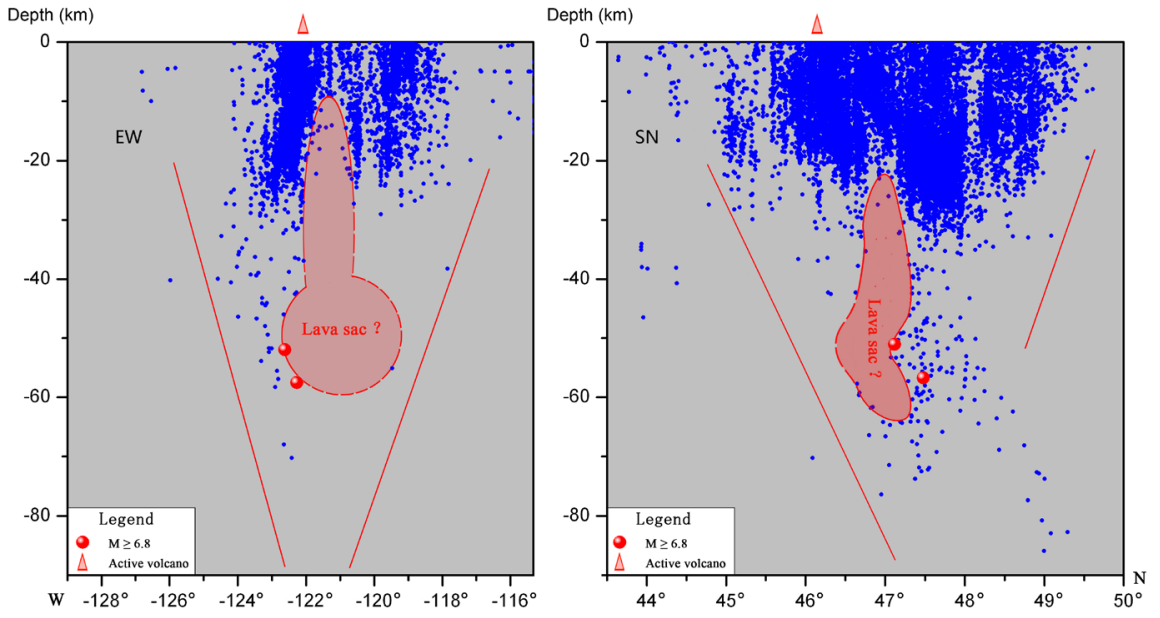

Figure 13. The deep structure sketch of Mount St. Helens (1965-2019.7, M $\geq 0.5$ ). 
seismic cone tectonic, which is the place out of the Erath of the seismic cone tectonic. Therefore, it is possible to find the storage lava sac of the active volcano through Benioff profile of the subcrustal earthquakes. Suspected lava sac has also been found in Ecuador's volcano and Italy's Mount Etna (Chen, 2015b, 2016b).

Before the 1980 and 2004 eruptions, earthquakes as large as M7 occurred at depths of $50+\mathrm{km}$. The strong quake, located near the suspected lava vesicles, may have been the direct cause of the eruption. The energy of strong earthquakes is unlikely to be related to surface fault activity, but most likely to be replenishment from deep sources. Deep energy can be replenishment in two forms: subcrustal seismic activity and convection of heat. The former can be monitored, while the latter cannot be monitored at present.

The last two eruptions of Mount St. Helens occurred 24 years apart, and the timing chart in Figure 5 suggests that eruptions are likely in coming years, requiring close attention to the strong seismic activity at depths of $40+\mathrm{km}$.

\subsection{Summary of 2019 M7.1 Earthquake Precursor Information}

The precursory information processing methods of the M7.1 earthquake on July 6, 2019, are summarized as follows:

1) The sequence diagram of subcrustal seismic activity within the Mini Seismic Cone Tectonic should have the trend line shown in Figure 7 to roughly judge the time domain of future strong earthquake activity or volcanic activity.

2) The surface projection of subcrustal seismic activity needs to distinguish between the outer zone and the inner zone according to Figures 8-11 to roughly judge the future strong earthquake activity area.

3) The ground projection of subcrustal seismic activity needs to judge the possibility and direction of migration according to Figure 12, and roughly judge the future strong earthquake activity location.

Two methods, 2) and 3), are used to roughly judge the active area of strong earthquakes in the future, while volcanoes, on the other hand, need not be concerned with location.

Above are medium-long-term forecasts.

4) In the short and imminent stage of earthquake or volcano prediction, the time and place of the future case should be judged according to a large number of local observation data of earthquake precursors and macroscopic anomalies.

According to the above working methods, the 2019 M7.1 earthquake may be predicted at least to the approximate time, location and intensity (M7士).

Admittedly, this working method is applicable to any seismic cone tectonic in the world but still needs to be verified by experience.

\subsection{Significance of Prediction Method of the Seismo-Geothermics}

The prediction method adopted in this paper captures the important information of subcrustal seismic activity. Subcrustal seismic activity is a symptom, not the whole, of a seismic cone or a mini seismic cone tectonic and can be detected. 
It can display a lot of information about cone activity, including the rhythm of cone activity, the process of bottom-up drive of cone, the lava capsule of volcano, the relationship between the surface projection of subcrustal earthquakes and the surface structure inside the shell, the critical time point of intracrustal strong earthquake and volcanic activity, etc. The animation image can also show the wonderful process of the stress state of the earthquake cylinder (Chen, 2012c).

It should be said that the method in this paper can obtain the most essential and direct warning signal, which has a great future.

\section{Conclusion}

In this paper, according to an earthquake catalogue ANSS data, using the principle and methods of Seismo-Geothermics for data processing of the west coast area of the United States and it's 2 mini seismic cone tectonics, using the plan distribution image, the three-dimensional images and the subcrustal earthquake sequence diagrams of overall earthquakes, intracrustal strong earthquakes, subcrustal earthquakes and volcanic activity in the study area, draws the following conclusions:

1) The west coast of the United States belongs to the core region of North American Seismic Cone Tectonic No. 24, and its seismic and volcanic activity state conforms to the concept of seismic cone tectonic, which can be divided 2 mini seismic cone tectonics for independent research.

2) U01 Mini Seismic Cone Tectonic is located in the Seattle area, which is dominated by the volcanic activity of Mount St. Helens, supplemented by M7士 strong seismic activity. There may be volcanic eruptions in the near future, so keep a close eye on the possible subcrustal strong seismic activity near the lava sac.

3) U02 Mini Seismic Cone Tectonic is located in the vast area from San Francisco to Los Angeles. It is mainly dominated by M7+ intracrustal strong seismic activity and migrates north and south along the San Andreas Fault. The surface projection of subcrustal seismic activity is divided into inner zone and outer zone distribution, which can indicate the migration direction of future strong earthquakes.

4) By the analysis and summary of the precursory information of M7.1 earthquake on July 6, 2019, it has given a basic method for handling similar events in the future. This method is applicable to the study of seismic cone tectonics in this paper, and all of the seismic cone tectonics on the Earth too.

Although the research method in this paper has certain advantages, studies in Italy, the Aegean Sea and the Northwest Pacific Ocean also yielded good results, but it is also limited by resources. At present, only high-precision local earthquake catalogues of the United States, the Mediterranean Sea and Japan can be obtained from the public network, while other regions can only use the M4+ ANSS earthquake catalogue, so the research is limited. The theoretical limitation 
of the Seismo-Geothermics lies in the understanding of the mechanism of subcrustal earthquakes and deep-source earthquakes. It is obviously unreasonable to introduce the elastic mechanics model of the earthquake in the shell into the deep part of the Earth. "Cavitation and cavitation dynamics" may help, but the author can't. Therefore, the research road of the Seismo-Geothermics is long and long, still need to strive for progress.

\section{Acknowledgements}

The author is thankful to the Northern California Earthquake Data Center, Smithson Institution for providing data as well as reference support from the National Library Reference Alliance (http://jour.ucdrs.superlib.net/).

\section{Conflicts of Interest}

The authors declare no conflicts of interest regarding the publication of this paper.

\section{References}

Chen, L. J. (2000). Research on Earthquake Focal Depth and Strong Earthquake Activity in China. Seismogeology, 22, 360-370.

Chen, L. J. (2012a). Principle and Application of Seismo-Geothermic Theory. Inland Earthquake, 26, 108-122.

Chen, L. J. (2012b). Preliminary Study on Earthquake Prediction Method for the West Coast of the United States. http://blog.sciencenet.cn/blog-552558-525866.html

Chen, L. J. (2012c). Seismic Prediction Verification Record No. 001: M6.9 Earthquake Occurred on 4.12 in the Gulf of California. http://blog.sciencenet.cn/blog-552558-558624.html

Chen, L. J. (2013a). Concept and Basic Characteristics of Seismic Cone Tectonic. South China Earthquake, 33, 1-14.

Chen, L. J. (2013b). Seismo-Tectonics and Seismic Activity of the Qinghai-Tibet Plateau. Journal of Seismological Research, 36, 123-131.

Chen, L. J. (2013c). Research on Subcrustal Seismic Activity (6): "La Madre" Phenomenon: Decadal and Annual Oscillation of Mantle (MDO). http://blog.sciencenet.cn/blog-552558-664926.html

Chen, L. J. (2013d). Mantle Decadal Oscillation (MDO). http://blog.sciencenet.cn/blog-552558-665664.html

Chen, L. J. (2015a). Pakistan Earthquake with Ms 7.7 in 2013 and Causative Structure of the Hindu Kush. Inland Earthquake, 29, 15-27.

Chen, L. J. (2015b). Comparative Study of Global Volcano Activities on the Hot Engine Belt and the Cooling Seismic Belt-Improvement on Research Ideas of Volcano Prediction on the Hot Engine Belt. Advances in Geosciences, 5, 334-357. (In Chinese) https://doi.org/10.12677/AG.2015.55034

Chen, L. J. (2015c). Summary of the Test of 0419 Forecast Card (3 Years) in 2012Recommend on the Methods of Intracrustal Strong Earthquake Prediction and Volcanic Prediction by the Theory of Seismo-Geothermic. Open Journal of Nature Science, 4, 147-164. https://doi.org/10.12677/OJNS.2015.34019 
Chen, L. J. (2016a). Study on the Seismogenic Mechanism of the Earthquake Mw6.9 in 2014 in the Aegean Sea Seismic Cone Tectonic. International Journal of Geosciences, 7, 669-684. https://doi.org/10.4236/ijg.2016.75052

Chen, L. J. (2016b). The Structure of Ecuador Seismic Cone and the Prediction Research of Earthquakes and Volcanoes. Open Journal of Natural Science, 4, 292-306.

Chen, L. J. (2016c). Seismic Activity and Seismic Cone Tectonics in the Coastal Region of Northwest Pacific Ocean. Advances in Geosciences, 6, 214-238. https://doi.org/10.12677/AG.2016.63024

Chen, L. J. (2016d). Study on Global Volcanic Activity Genesis and Its Classification. Hans Preprint. https://doi.org/10.12677/HANSPrePrints.2016.11020

Chen, L. J. (2016e). Seismic Cone Type Eruption Characteristics. http://blog.sciencenet.cn/blog-552558-983911.html

Chen, L. J. (2016f). Mantle Plume Type Eruption Features. http://blog.sciencenet.cn/blog-552558-982026.html

Chen, L. J. (2019a). California M7.1 Earthquake on July 6, 2019, Maybe Predicted. http://blog.sina.com.cn/s/blog_41478bf40102yqla.html

Chen, L. J. (2019b). On Seismicity in Songyuan Region and the Hunchun Seismic Cone Tectonic in Jilin Province, China. Open Journal of Nature Science, 7, 429-438. https://doi.org/10.12677/OJNS.2019.75052 http://blog.sciencenet.cn/blog-552558-1185874.html

Chen, L. J., Chen, X. F., \& Shao, L. (2015b). Method Research of Earthquake Prediction and Volcano Prediction in Italy. International Journal of Geosciences, 6, 963-971. https://doi.org/10.4236/ijg.2015.69076

Chen, L. J., Chen, X. F., Wan, F. F., Li, P. Z., \& Shao, L. (2015a). Comparative Study of Global Seismicity on the Hot Engine Belt and the Cooling Seismic Belt-Improvement on Research Ideas of Earthquake Prediction. International Journal of Geosciences, 6, 741-749. https://doi.org/10.4236/ijg.2015.67060

Chen, L. J., Hu, F. X., \& Chen, X. F. (2013). Seismic Tomography Evidence of Global Seismic Cone Tectonics. South China Earthquake, 33, 1-10.

Huang, J. L., \& Zhao, D. P. (2003). P-Wave Tomography of Crust and Upper Mantle under Southern California: Influence of Topography of Moho Discontinuity. Acta Seismologica Sinica, 25, 563-573. https://doi.org/10.1007/s11589-003-0041-6

Luo, Z. L., Qian, H., \& Wen, X. Z. (1987). Seismic and Geological Comparison of Xianshuihe Fault and San Andres Fault. Sichuan Earthquake, No. 4, 1-10. (In Chinese)

Smithsonian Institution (2015). Global Volcanism Program. http://volcano.si.edu/index.cfm

USGS (2019). M7.1-18km W of Searles Valley, $C A$. https://earthquake.usgs.gov/earthquakes/eventpage/ci38457511/executive 